\title{
STRUCTURAL ASSESSMENT OF FML AEROSTRUCTURES WITH INTEGRATED ELECTROMAGNETIC FEATURES
}

\author{
EMUS 2020 \\ J.F. de FREITAS ${ }^{*}$, C. van HENGEL ${ }^{*}$, P. HOMOLA ${ }^{\dagger}$ \\ ${ }^{*}$ GKN Fokker Aerostructures \\ Industrieweg 4, 3351 LB Papendrecht, The Netherlands \\ Email: joao.defreitas@,fokker.com; Email: cees.vanhengel@,fokker.com \\ Webpage: http://www.gknaerospace.com \\ $\dagger$ VZLU Aerospace Research and Test Establishment \\ Beranových 130, 19005 Praha - Letnany, Czech Republic \\ Email: homola@vzlu.cz \\ Webpage: https://www.vzlu.cz
}

Key words: Structural behavior, GLARE, integrated slot antenna, structural element testing

\begin{abstract}
A substantial contribution to reduce the aerodynamic drag and consequent $\mathrm{CO}_{2}$ and $\mathrm{NO}_{\mathrm{x}}$ emissions is to integrate communication antennas in the aircraft structure. This paper presents a GLARE fuselage panel design for an integrated VHF slot antenna and discusses the results of a mechanical experimental campaign on a structural element level, in quasi-static tensile conditions. The tested specimens showed small variability in terms of stiffness and strength (typical for GLARE), little dependence on the ambient conditions, damage presence, and layup configurations and good agreement with early numerical simulations. In addition, stiffness and strength predictions, based on empirically found design values seem to correlate well with the found test values.
\end{abstract}

\section{INTRODUCTION}

Conventional aircraft VHF communication and GNSS antennas are (fin- and teardropshaped, respectively) protruding structures, containing electromagnetic equipment, typically assembled on top of the aircraft fuselage. These structures disturb the airflow around the fuselage, increasing the aerodynamic (friction and pressure) drag, which ultimately translates into a greater fuel consumption.

In an effort to mitigate this undesired effect, the ACASIAS project develops innovative integrated antenna solutions in the aerostructures. In this context, GLAss fiber REinforced aluminium laminate (GLARE) offers a large design freedom in tailoring the material to very specific electromagnetic, structural and manufacturing requirements. Most importantly, GLARE provides a unique material opportunity for a slot antenna application.

A slot antenna works under the principle of electromagnetic wave radiation around the slot by an induced radio frequency current. The optimal length for an air-filled slot antenna is half a wavelength [1]. However, for electromagnetic (for higher permittivity) and structural integrity (for higher load carrying capacity and durability) reasons, the selected solution for the slot is similar to a 'patch-repair' but with the Glass Fiber Reinforced Epoxy (GFRE) layers interspersed with the aluminium sheets [Figure $1 \mathrm{c}$ )] allowing smooth load paths, thus avoiding pronounced stress concentrations. 
This paper aims to assess the structural behavior of the integrated slot antenna solution in a GLARE panel, through an experimental approach backed by simple stiffness and strength predictions. The article is structured as follows: section 2 elaborates on the structural design of the integrated antenna, motivating its design and material choices, where the mechanical properties of GLARE are examined. Section 3 briefly sets the experimental methodology for the quasi-static testing of the structural elements, including the instrumentation used. In section 4 , results are presented and discussed. Section 5 draws the conclusions from this study.

\section{STRUCTURAL DESIGN OF AN INTEGRATED VHF ANTENNA}

\subsection{Geometry and size}

The length of the slot affects the resonance frequency of the antenna. In addition, the shape of the antenna influences the radiation pattern. The optimal length for an air-surrounded slot antenna is half a wavelength. However, because a higher permittivity epoxy-filled Parallel Plate Resonator (PPR) was coupled inside the fuselage to reflect back the radio waves to the exterior of the aircraft ${ }^{1}$, the optimum length of the slot had to be found through simulations carried out by the NLR [1].

The proposed design for the integrated VHF slot antenna in a fuselage panel comprises a smooth transition from a 1.4mm thick GLARE 3 (in light blue - Figure 1) to a $3.5 \mathrm{~mm}$ thick fullS2/ GFRE (in orange -Figure 1). The ring region in between these two materials consists of plydrop transitions (in green - Figure 1) design
and consequent undesirable stress congen trations
a)
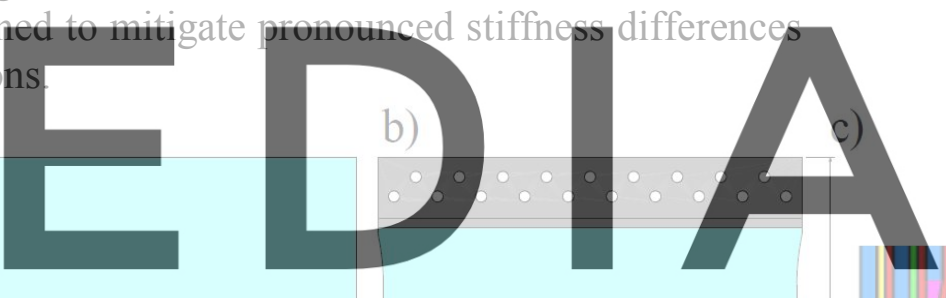

Register for free at https//www.scipedia.com to download the version without the watermark
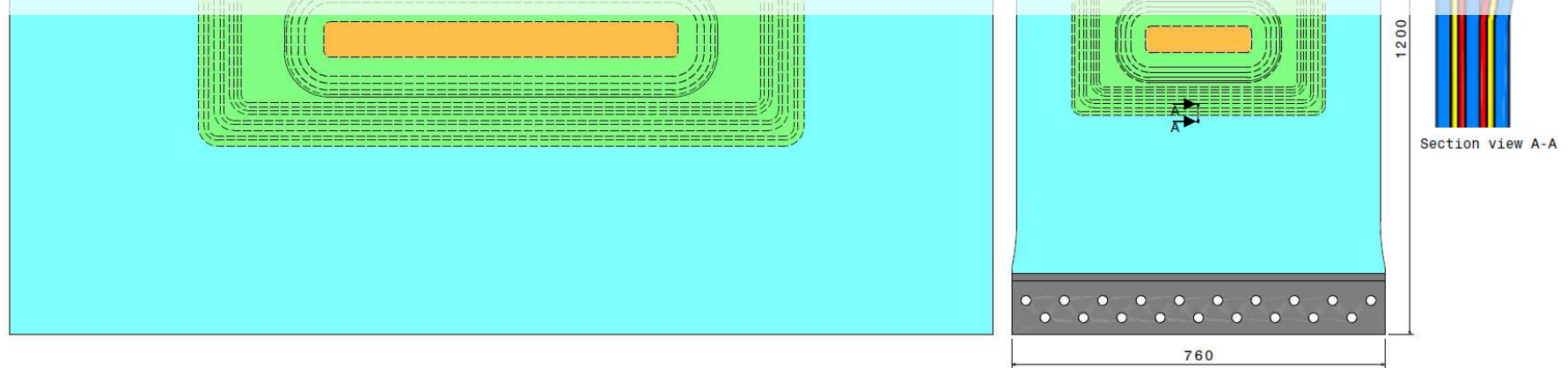

Figure 1: Panel drawings: a) demonstrator panel; b) test panel; four different regions and corresponding materials are color coded: GLARE 3 in light blue, S2/GFRE in orange, GLARE 3 - GFRE transition in green and aluminium bonded tabs in gray c) section view A-A: ply drop detail.

\subsection{Material properties and layup configurations}

GLARE is a Fiber Metal Laminate (FML) material for advanced aerospace applications, composed of thin 2024-T3 aluminium alloy sheets interspersed with unidirectional layers of

\footnotetext{
${ }^{1}$ These waves would otherwise propagate to the interior of the aircraft.
} 
GFRE prepreg, where the epoxy resin bonds the metal sheets and the glass fiber layers together (Figure 2). This material exhibits unique features, namely: exceptional fatigue properties [2], specifically due to slower crack growth behavior (through fiber bridging phenomenon - Figure 3 - that reduces the stress intensity at the crack tip in the aluminium layers) [3] and high impact, corrosion- and fire-resistances [2].

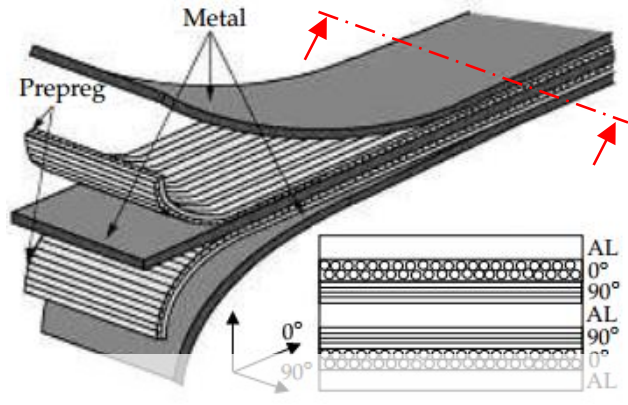

Figure 2: FML material diagram.

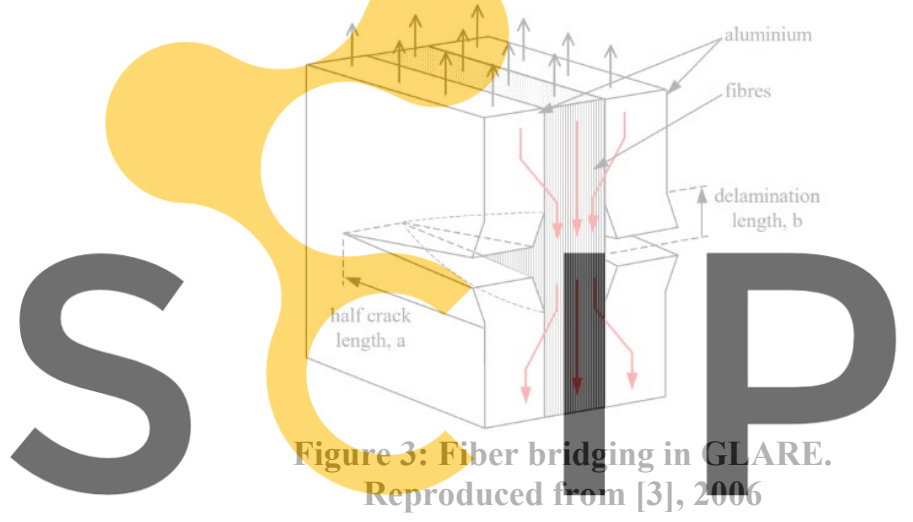

Table 1: Material properties of GLARE 3.

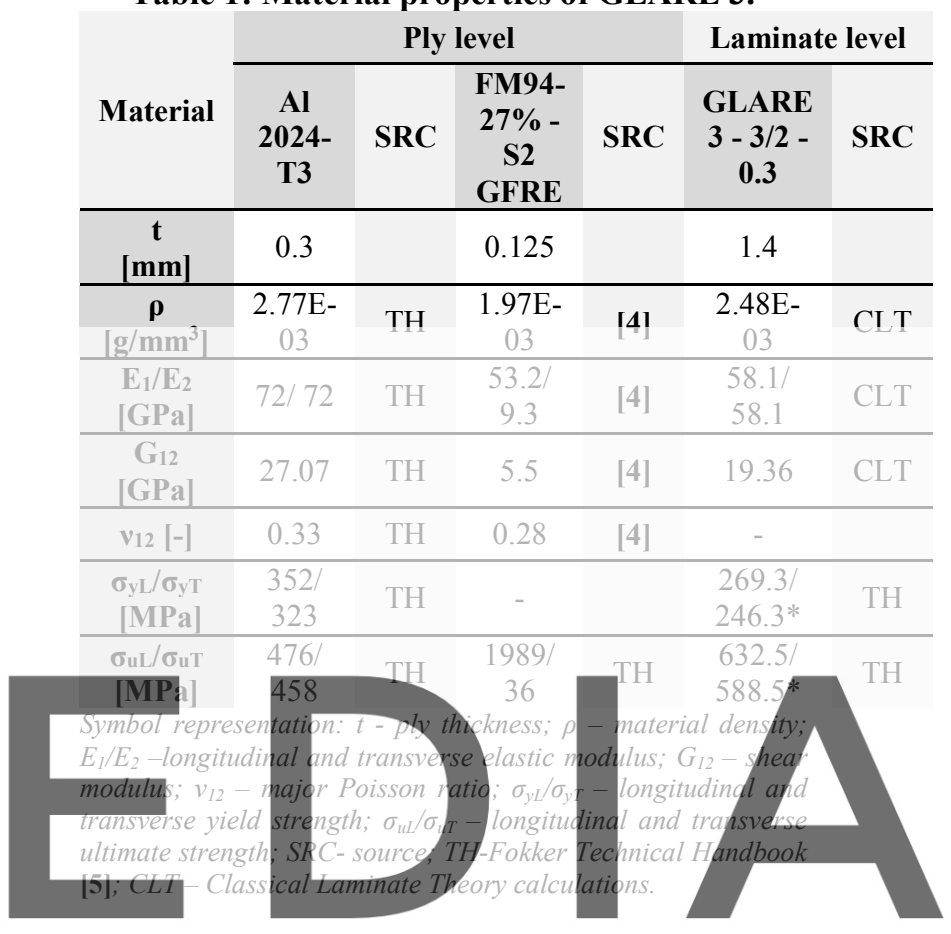

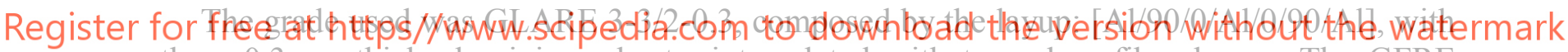
three $0.3 \mathrm{~mm}$ thick aluminium sheets, intercalated with two glass fiber layers. The GFRE constituent material is made of FM94 epoxy resin, that cures at $120^{\circ} \mathrm{C}$, reinforced by unidirectional high strength S2 glass fibers with a fiber volume content between $52 \%$ and $72 \%$ [5]. Table 1 presents the material properties of the constituents of GLARE, on a ply-level and of GLARE 3-3/2-0.3, on a laminated level. This material shows a longitudinal membrane stiffness $\left(\mathrm{A}_{11}\right)$ of $88.56 \mathrm{GPa} . \mathrm{mm}$. The stiffness and strength of GLARE is therefore tailored by the type of prepreg material, composition, stacking sequence and thickness of the laminate.

Typically, the failure mechanism of GLARE 3, under quasi-static tensile loading and assuming isostrain conditions, is as follows: at an engineering strain of $\sim 0.5 \%$, the aluminium starts to plastically deform and to redistribute the stresses to the adjacent GFRE plies. For an increasing applied load, damage will eventually start as matrix cracking that may coalesce into delaminations; further increasing the load will lead to the ultimate failure of the laminate, at a strain of $\sim 4.5 \%$ [6], due to glass fiber breakage of the $0^{\circ}$ oriented layers.

Three $3.5 \mathrm{~mm}$ thick layup configurations, each containing 28 GFRE plies, were structurally assessed for panel design (specifically in the slot region). The following list presents their layup configurations together with the longitudinal membrane stiffness and elastic modulus values:

- A: $[90 / 0 / 90 / 0 / 90 / 0 / 90 / 0 / 90 / 0 / 90 / 0 / 90 / 0]_{s} ; A_{11}{ }_{A}=110.9$ GPa.mm; $E_{m 1} \mathrm{~A}=31.47 \mathrm{GPa}$;

- B: $[0 / 90 / 90 / 0 / 90 / 0 / 90 / 90 / 0 / 90 / 0 / 90 / 0 / 90]_{s} ; \mathrm{A}_{11 \_\mathrm{B}}=99.8 \mathrm{GPa} . \mathrm{mm} ; \mathrm{E}_{\mathrm{m} 1 \_\mathrm{B}}=28.31 \mathrm{GPa}$;

- C: $[90 / 0 / 0 / 90 / 0 / 90 / 0 / 0 / 90 / 0 / 90 / 0 / 90 / 0]_{\mathrm{s}} ; \mathrm{A}_{11} \mathrm{C}=122.0 \mathrm{GPa} . \mathrm{mm} ; \mathrm{E}_{\mathrm{m} 1 \mathrm{C}}=34.61 \mathrm{GPa}$. 


\section{MECHANICAL STATIC TESTING OF STRUCTURAL ELEMENTS}

The structural behavior and strength of aerostructures is assessed through a series of tests of increasing size, cost, time and complexity, represented by the 'building block' approach (also known as 'testing pyramid' - Figure 4). This comprehensive and systematic methodology sets a logical framework for airworthiness qualification and structural integrity demonstration. In other words, it is the backbone of aerostructures certification [7].

For the ACASIAS project, the first three levels of the pyramid were considered:

1) Coupon - material properties such as strength values and elastic properties are extracted and used to calibrate the material model;

2) Structural elements - empirical 'knock-down factors' are derived, related to environmental, scatter and damage effects; in addition, the global structural behavior and strength data are determined and can be used as design values;

3) Details [see test panel - Figure $1 \mathrm{~b}$ )] - the structural performance of the FEA predictions are compared against experimental tests of a much representative test specimen and a thorough structural understanding is reached. Testing at panel level is currently ongoing and will be reported in a future paper.

The present article will solely focus on the Mechanical Static Testing (MST), at the structural element level, in tensile conditions. All tests were performed at VZLU in Prague.

\subsection{Test description and test matrix}

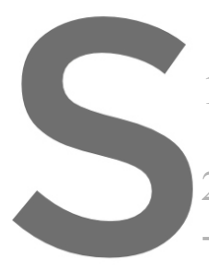

The structural elements $1 \mathrm{~mm} / \mathrm{min}$ (i.e. in quasi-s

Three layup configu

2): a) Room Temperatu $\left.-55^{\circ} \mathrm{C}\right)$; c) Hot Tempera
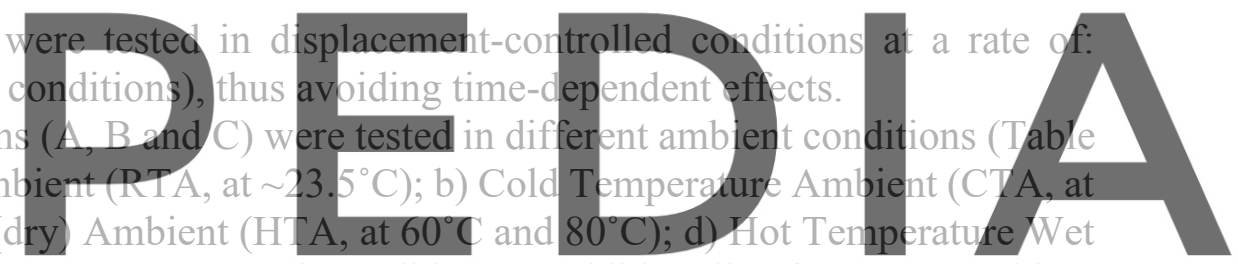

(HTW, at $60^{\circ} \mathrm{C}$ and $80^{\circ} \mathrm{C}$ in water saturated conditions). Additionally, for some ambient

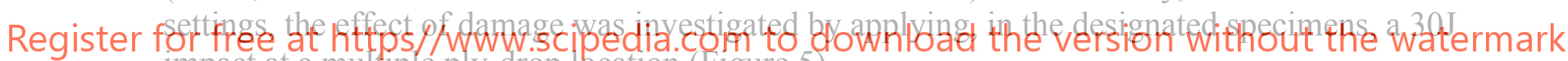
impact at a multiple ply-drop location (Figure 5).

Table 2 also mentions structural elements that included an integrated Flexible Printed

Circuit Board (Flex-PCB) to assess its effects in the structural performance of the specimens and the repercussions of high load introduction in the electrical continuity of the wires. However, the scope of the present article does not encompass those results.

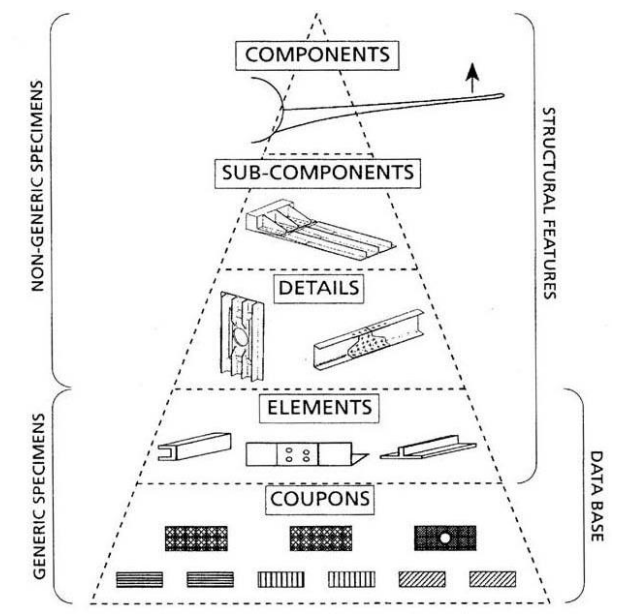

Table 2: Structural element test matrix.

\begin{tabular}{|c|c|c|c|c|c|c|c|c|}
\hline \multirow[t]{2}{*}{ Conf. } & \multicolumn{2}{|c|}{$\begin{array}{c}\text { RTA } \\
{\left[\sim 23.5^{\circ} \mathrm{C}\right]} \\
\end{array}$} & \multicolumn{2}{|c|}{$\begin{array}{c}\text { CTA } \\
{\left[-55^{\circ} \mathrm{C}\right]} \\
\end{array}$} & \multicolumn{2}{|c|}{$\begin{array}{l}\text { HTA }\left[60^{\circ} \mathrm{C}\right] \\
\text { HTA }\left[80^{\circ} \mathrm{C}\right] \\
\end{array}$} & \multicolumn{2}{|c|}{$\begin{array}{l}\mathrm{HTW}\left[60^{\circ} \mathrm{C}\right] \\
\mathrm{HTW}\left[80^{\circ} \mathrm{C}\right] \\
\end{array}$} \\
\hline & Pris. & Imp. & Pris. & Imp. & Pris. & Imp. & Pris. & Imp. \\
\hline \multirow{2}{*}{$\mathbf{A}$} & \multirow{2}{*}{2} & \multirow{2}{*}{1} & \multirow{2}{*}{2} & \multirow[b]{2}{*}{-} & 1 & - & 1 & 1 \\
\hline & & & & & 1 & - & 1 & 1 \\
\hline \multirow{2}{*}{ B } & \multirow{2}{*}{$2(1)$} & \multirow{2}{*}{ 1(1) } & \multirow{2}{*}{2} & \multirow[b]{2}{*}{ - } & 1 & - & 1 & 1 \\
\hline & & & & & $1(1)$ & - & 1 & 1 \\
\hline \multirow{2}{*}{ C } & \multirow{2}{*}{$2(1)$} & \multirow{2}{*}{$1(1)$} & \multirow{2}{*}{2} & \multirow[b]{2}{*}{ - } & 1 & - & 1 & 1 \\
\hline & & & & & $1(1)$ & - & 1 & 1 \\
\hline Total & $6(2)$ & $3(2)$ & 6 & - & $6(2)$ & - & 6 & 6 \\
\hline
\end{tabular}

Figure 4: Aerostructures testing pyramid. 


\subsection{Structural element specimens and instrumentation}

The structural element specimens were $700 \mathrm{~mm}$ long by $100 \mathrm{~mm}$ wide (Figure 5). The effective length of the specimen was $590 \mathrm{~mm}$, provided that the gripping length on each end was $55 \mathrm{~mm}$ long.

Global load-displacement and localized strain data were acquired by the use of the instrumentation contained and described in Table 3. The exact location of the strain gauges is shown in Figure 5.
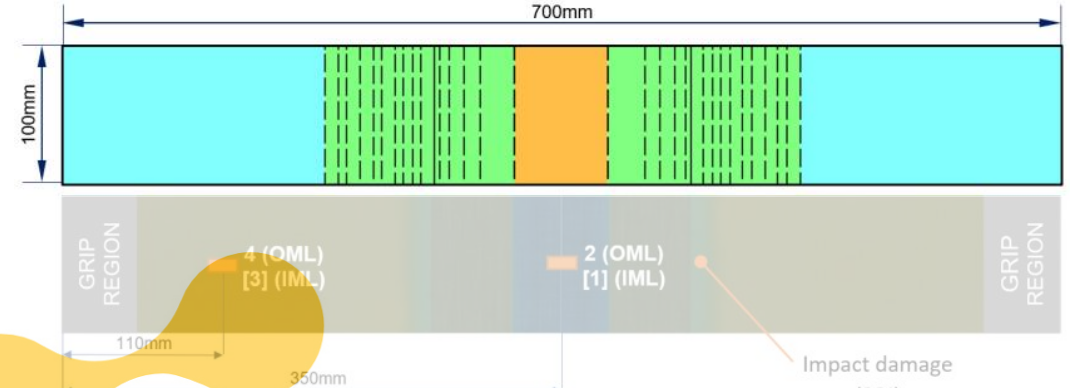

(30J)

Figure 5: Structural element test specimen - OML view: drawing showing material regions (top) and photo with specified strain gauge, grip and impact locations (bottom).
Table 3: Instrumentation used in the MST.

\begin{tabular}{cc} 
Data description: & Sensor: \\
\hline Applied load [N] & Load cell \\
\hline $\begin{array}{c}\text { Global } \\
\text { displacement [mm] }\end{array}$ & Acting piston \\
\hline Localized strains & $\begin{array}{c}\text { 4x Strain gauges } \\
\text { (longitudinal) at } \\
\text { specified locations }\end{array}$ \\
\hline $\begin{array}{c}\text { Inplane strain field } \\
\text { and out-of-plane } \\
\text { deflection }\end{array}$ & $\begin{array}{c}\text { 2x DIC cameras } \\
\text { at OML surface }\end{array}$ \\
\hline $\begin{array}{c}40,000 \text { fps video of } \\
\text { failure }\end{array}$ & High speed camera
\end{tabular}
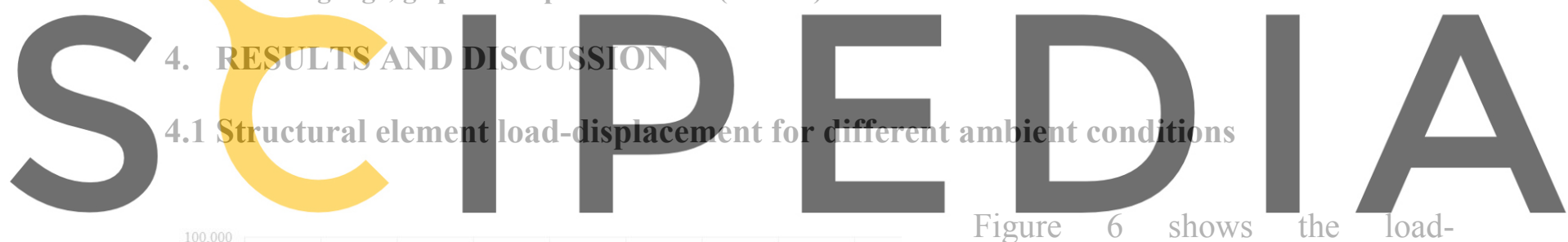

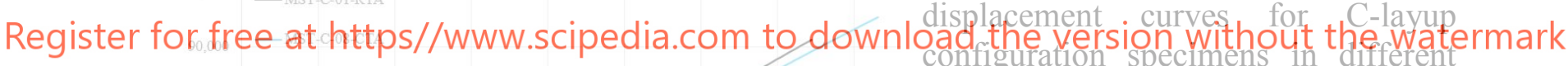

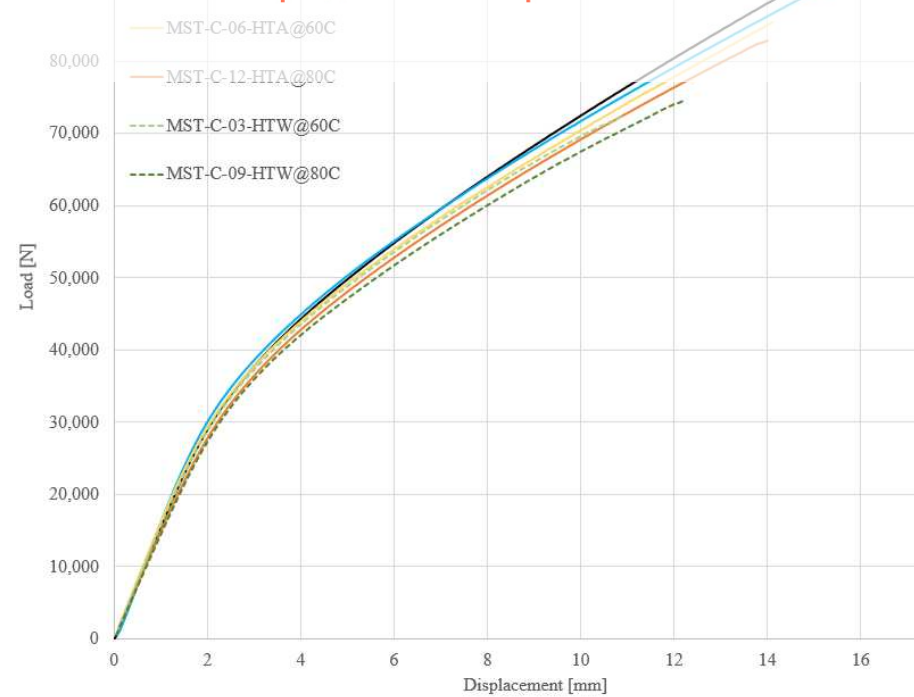

Figure 6: Load-displacement curves of C-configuration structural element specimens tested at different ambient conditions. ambient conditions. In the elastic region, the structural behavior was very similar in all cases, with small differences in stiffness $(\sim 13 \%$ between CTA and HTW@80 $80^{\circ}$ ). After the yielding point, the stiffness changes became slightly more noticeable, with a stiffer and stronger structural behavior for decreasing temperature and water content; except for the specimen in CTA, which showed to be more compliant than the specimen in RTA after yielding.

The global behavior and strength of the structural element is dominated (yet, not identical) by GLARE structural properties. 


\subsection{Experimental vs. numerical stress strain curves for GLARE and GFRE regions}

Ongoing simulations ${ }^{2}$ carried out by CIMNE [8] [in grey and in black, for GFRE and GLARE regions, respectively - Figure 7 a)] show a very good agreement with the strain gauge data and DIC results, particularly for GLARE. Differences between GFRE strain gauge readings on the OML and IML surfaces indicate that the specimen deflected due to bending. From DIC, the measured out-of-plane displacement in the center was of $\sim 1.45 \mathrm{~mm}$ (in the positive normal direction of the OML plane). This secondary bending behavior originates due to the laminate's asymmetrical build-up, which induces load-path eccentricities.

GLARE 3 elastic modulus extracted by the DIC results was of $\sim 54.5 \mathrm{GPa}$ which is $\sim 6.2 \%$ lower than the theoretically determined, through Classical Laminate Theory (CLT) of 58.1 GPa (see Table 1). Yielding was determined by processing the DIC data and assuming the commonly used $0.2 \%$ offset strain as the criterion: the found yield value was of $\sim 259 \mathrm{MPa}$, which is $\sim 3.8 \%$ lower than the theoretical value of $269.3 \mathrm{MPa}$, calculated by using the rule of mixtures ${ }^{3}$ by combining the individual yield values present in the internal Technical Handbook (TH) [5].

Regarding the ultimate strength, the load cell measured a maximum value of $91.23 \mathrm{kN}$, which in terms of average engineering stress is equal to $651.6 \mathrm{MPa}$, i.e., $\sim 3.0 \%$ higher than the computed theoretical value of 632.5 MPa (using the same method as for the yielding - Table 1).

The longitudinal engineering strain field is presented in Figure $7 \mathrm{~b}$ ), which shows a more compliant behavior of GLARE 3 against a much stiffer behavior of the thicker GFRE, justified

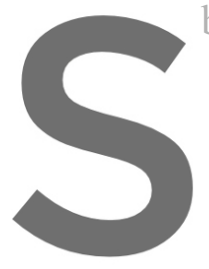
by the lower longitudina
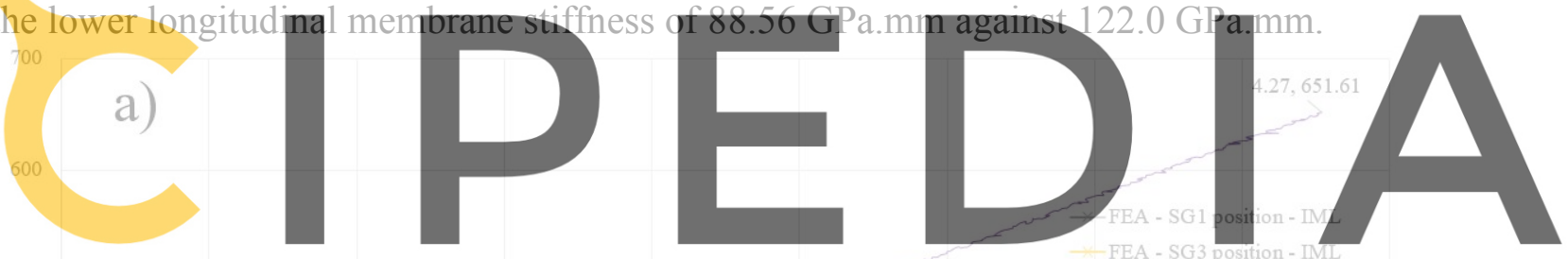

Register forfree at https//www.scipedia.com to download the version without the watermark

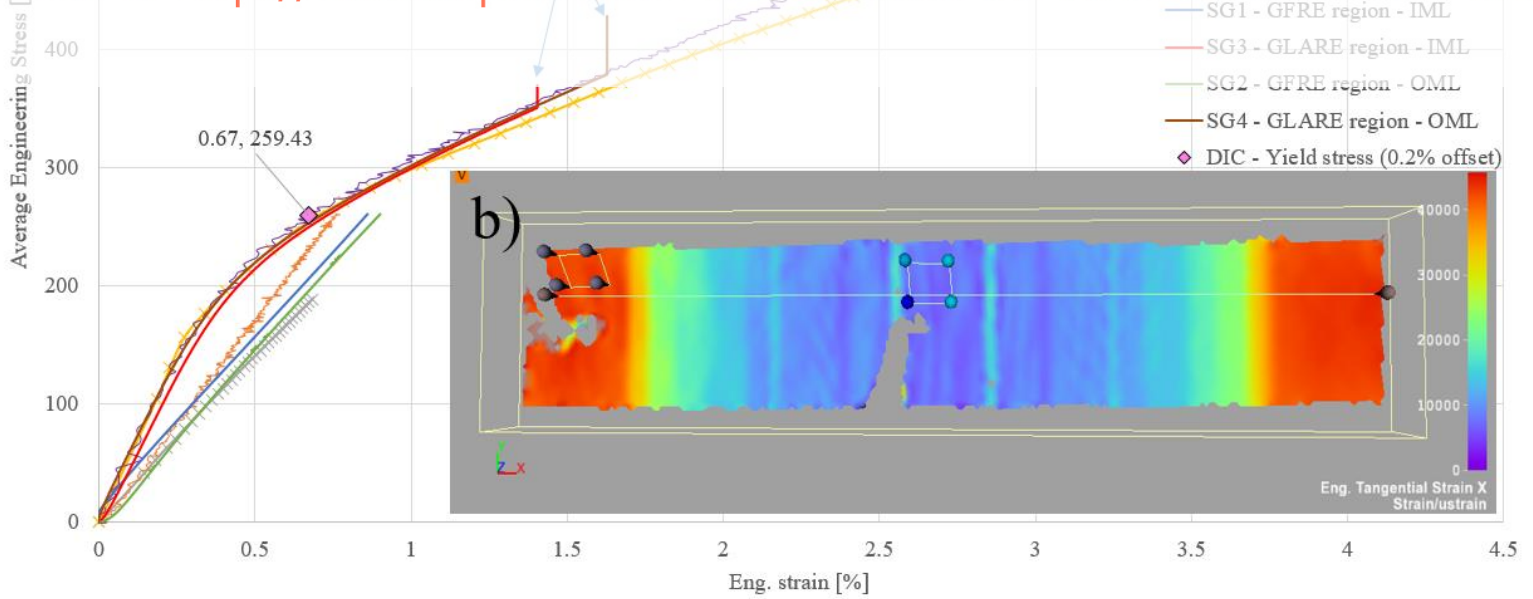

Figure 7: a) Stress-strain curves for: FEA predictions, DIC and strain gauge measurements; at GLARE and GFRE regions of test specimen MST-C-01; b) Longitudinal engineering strain field at maximum load.

\footnotetext{
${ }^{2}$ The last data point in CIMNE simulations does not represent failure, but an interrupted simulation due to lengthy convergence attempts.

${ }^{3}$ The rule of mixtures rely on the assumption that the mechanical properties of the material can expressed by simple linear functions of the metal volume fraction.
} 


\subsection{Overview on the maximum loads and failure modes}

Having the dry RTA condition as a reference, the maximum load bar chart (Figure 8 ) shows a $\sim 11.8 \%$ strength decrease for a dry specimen tested at $80^{\circ} \mathrm{C}$. The drop in strength due to saturated conditions was of $\sim 12.2 \%$ and $\sim 11.2 \%$ for specimens, at $60^{\circ} \mathrm{C}$ and $80^{\circ} \mathrm{C}$, respectively, when directly compared to their dry counterparts. An impact of $30 \mathrm{~J}$ did not seem to affect the strength of the tested samples, as the decrease in average strength was always lower than $1.5 \%$.

Out of the 33 tested specimens, all failed in GLARE net cross-section: 16 of those failed at the first ply-drop (due to the stress concentration effect); seven, somewhere in thinnest GLARE region; and ten failed in the gripping region (including all six CTA specimens). This means that $70 \%$ of the specimens failed as intended, in the well-studied GLARE region. To mitigate the occurrence of the undesired gripping failure, subsequent tests will include tapered tabs.

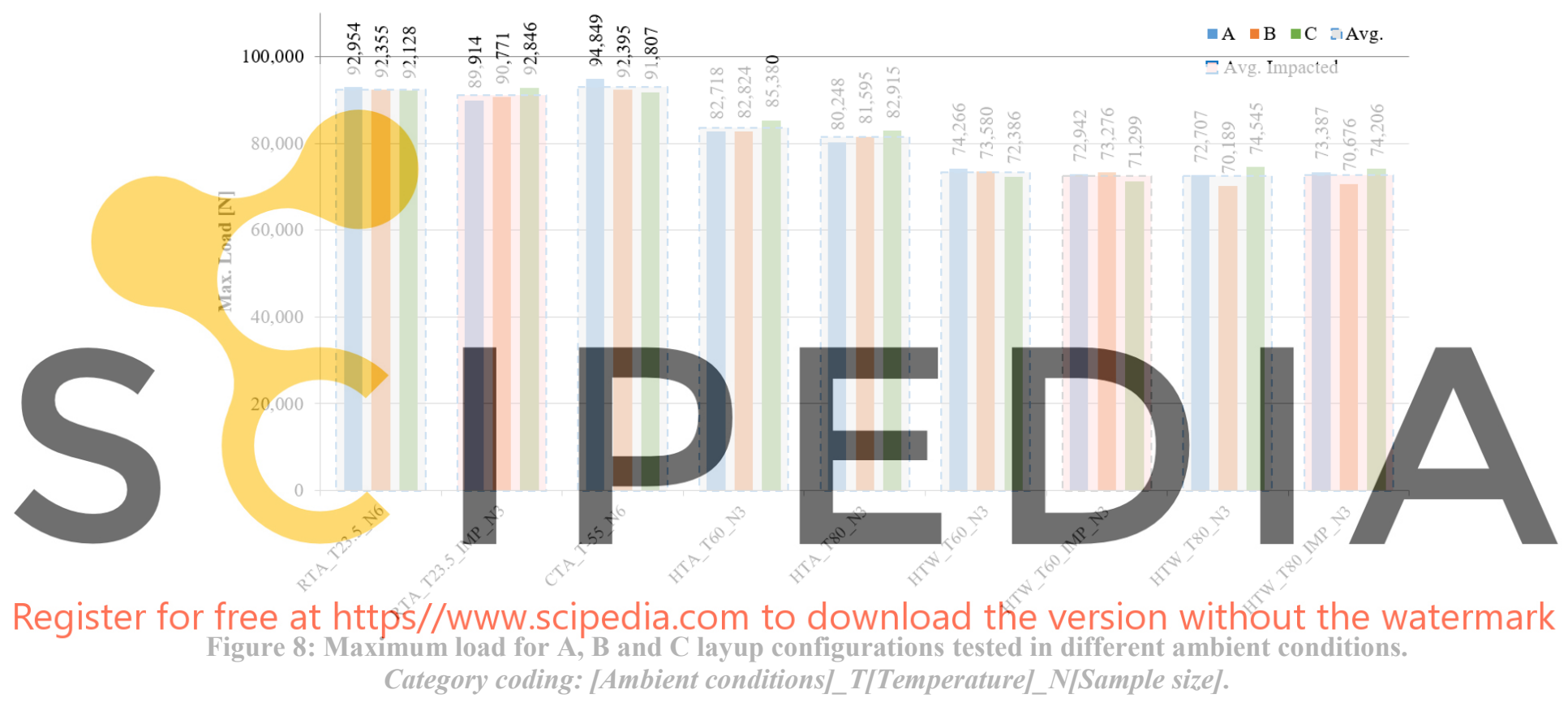

\section{CONCLUSIONS}

This paper aimed to assess the structural behavior of an integrated slot antenna in a GLARE fuselage panel. From the result analysis of an experimental campaign carried at the structural element level, in quasi-static tensile conditions, the following conclusions were drawn:

- Design values found in internal technical handbooks seem to predict very accurately $(\sim 2.9 \%$ lower $)$ the found failure load in GLARE. Additionally, CIMNE early simulations seem to accurately predict the behavior of the structural elements. The following numerical stress analysis work should focus on predicting damage initiation and ultimate failure.

- The structural elements behavior is dominated by GLARE; moreover, the stiffness and strength of the structural elements are barely affected by layup configuration, impacting damage $(<1.5 \%$ weaker than pristine counterparts $)$, temperature $(\sim 11.8 \%$ weaker than RTA counterparts) and water content ( $\sim 11.2 \%$ weaker than dry counterparts).

- The dominant failure mode was net-cross section in GLARE, particularly in the intended first ply-drop (16/33 specimens) due to the stress concentration. Provisions were taken to avoid gripping failure in next testing stages, as the inclusion of tapered tabs. 


\section{ACKNOWLEDGEMENTS}

We thank our production colleagues from GKN-Fokker and VZLU for the dedication and provided support in the manufacturing and testing of the test specimens that made possible the obtainment of the presented results.

This project has received funding from the European Union's Horizon2020 research and innovation programme under grant agreement No.723167.

\section{REFERENCES}

[1] J. Rotgerink, C. Heuts, J. Verpoorte and C. van Hengel, "VHF antenna integrated into a classical fibre metal laminate fuselage panel.," in European Conference on Multifunctional Structures, Barcelona, 2020.

[2] G. Wu and J. Yang, "The Mechanical Behavior of GLARE Laminates for Aircraft Structures," Journal of the Minerals, Metals and Materials Society, pp. 72-79, 2005.

[3] R. Alderliesten and J. Homan, "Fatigue and damage tolerance issues of Glare in aircraft structures.," International Journal of Fatigue, vol. 28, pp. 1116-1123, 2006.

[4] R. Citarella, E. Armentani, R. Sepe and F. Caputo, "FEM Simulation of a FML Full Scale Aeronautic Panel Undergoing Static Load," Industrial Engineering \& Management, vol. 3, no. 1,2014

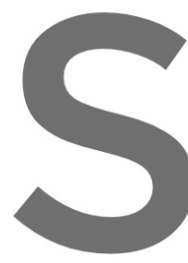

[5] Fokker Aerostructur standard GLARE

[6] M. Hagenbeek, ' Loadings," TU Delf , n t

[7] University of Bristel,
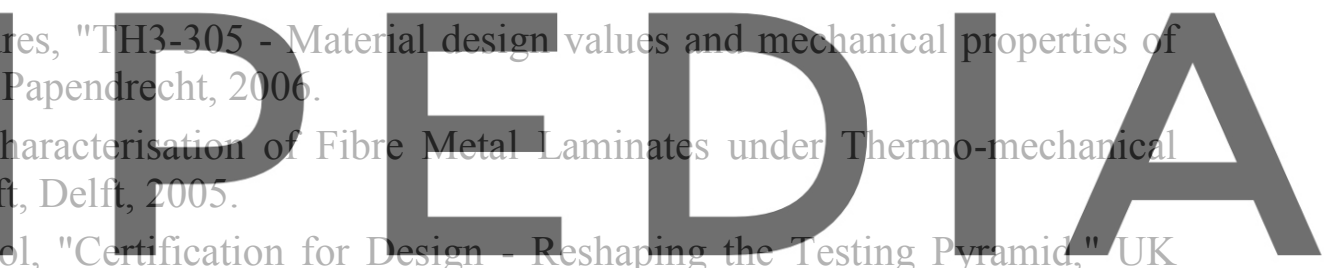

Research and innovation, Swindon, 2020.

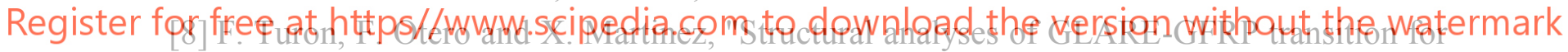
integrated VHF antenna on a fuselage panel," in European Conference on Multifunctional Struciures, Barcelona, 2020. 